\title{
How small studies mislead us
}

Joanna Chikwe, MD, ${ }^{\mathrm{a}, \mathrm{b}}$ and Shinobu Itagaki, MS, MD

\author{
From the a Department of Cardiovascular Surgery, Mount Sinai Medical Center, New York, NY; and ${ }^{\mathrm{b}}$ Department \\ of Surgery, The State University of New York, Stony Brook, NY. \\ Disclosures: Authors have nothing to disclose with regard to commercial support. \\ Received for publication June 4, 2018; revisions received June 4, 2018; accepted for publication June 4, 2018; \\ available ahead of print July 24, 2018. \\ Address for reprints: Joanna Chikwe, MD, Department of Cardiovascular Surgery, Mount Sinai Medical Center, \\ 1190 Fifth Ave, New York, NY 10029 (E-mail: Joanna.Chikwe@mountsinai.org). \\ J Thorac Cardiovasc Surg 2018;156:1808-9 \\ $0022-5223 / \$ 36.00$ \\ Copyright (c) 2018 Published by Elsevier Inc. on behalf of The American Association for Thoracic Surgery \\ https://doi.org/10.1016/j.jtcvs.2018.06.010
}

What is the problem with small studies? Our specialty evolved through change and innovation published as case reports and series, and although these have been augmented recently by increasingly large registries and randomized trials, most cardiothoracic research still consists of comparisons of a few hundred patients.

For example, in this issue of the Journal, Patel and colleagues ${ }^{1}$ report $0.5 \%$ mortality after coronary artery bypass grafting and $0.5 \%$ mortality after a hybrid procedure in 207 propensity-matched patients pairs $(P=1.0)$, concluding these procedures are associated with equivalent outcomes. The problems with this kind of study have recently been highlighted in critiques (Figure 1) suggesting that most conclusions drawn from such research are unreliable for reasons including low statistical power. ${ }^{2,3}$

Imagine a manufacturer making thousands of cars at 2 factories. The manufacturer discovers that $0.5 \%$ of the cars made at 1 factory have a lethal construction fault. They stop production and recall all cars made at that factory. How many cars made at the second factory should they recall, and how many faults should they find, to prove both factories have the same problem?

Recalling and examining every car made by the second factory is the only way to be $100 \%$ sure. An alternative is recalling several thousand cars: the same $0.5 \%$ fault rate in a sample of that size indicates the factories very likely have the same problem, whereas forming this conclusion after finding one fault in a 200-car sample from the second factory is the equivalent of the study by Patel and colleagues.

The problem is that even if the lethal fault rate at the second factory was many times higher or lower than $0.5 \%$, there is clearly a fair chance that a random sample of 200 cars from the second factory might contain one single faulty car. In other words, although the 200-car sample suggests both factories have identical $0.5 \%$ fault rates, there could really be a difference between the factories that this small sample failed to detect-a false negative. The probability

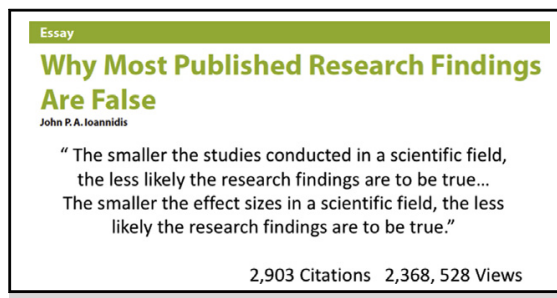

Prevailing bias and research methodology produce misleading results in biomedical research.

\section{Central Message}

Most conclusions drawn from small comparative studies are unreliable, primarily because low statistical power increases the risk of false-negative results.

See Article page 1799. of a false negative is reduced (and the power of the study to identify a true difference is increased) if the sample is very large, or the event rate being compared is very high.

Therefore, there is a real possibility that hybrid revascularization could result in much better or much worse outcomes than conventional surgery-we simply cannot tell because the number of events in the study by Patel and colleagues ${ }^{1}$ is too small for reliable comparison. Either the study needs more patients (thousands), a more frequent primary endpoint (such as a composite of long-term mortality, repeat revascularization, stroke, and myocardial infarction), or both.

This is why the randomized Hybrid Coronary Revascularization Trial is designed to recruit 2354 patients, comparing a composite end point (5-year all-cause mortality, myocardial infarction, stroke, and unplanned revascularization). ${ }^{4}$ The trial is designed to have sufficient patients and "power" to reduce the risk of a

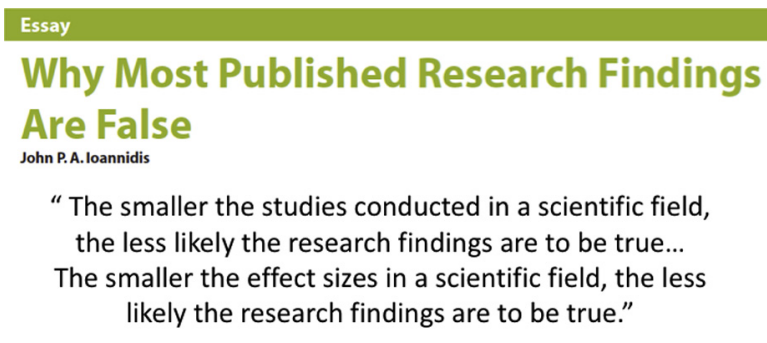

2,903 Citations 2,368, 528 Views

FIGURE 1. In one of the most highly cited articles published, Ioannidis ${ }^{2}$ outlines how prevailing bias and research methodology combine to produce misleading results in much, if not most, biomedical research. 
false-negative result. Low statistical power is first in a catalogue of reasons why small studies frequently mislead us.

\section{References}

1. Patel NC, Hemli JM, Kim MC, Seetharam K, Pirelli L, Brinster DR, et al. Shortand intermediate-term outcomes of hybrid coronary revascularization for doublevessel disease. J Thorac Cardiovasc Surg. 2018;156:1799-807.
2. Ioannidis JP. Why most published research findings are false. PLoS Med. 2005;2: e124.

3. Ioannidis JP, Greenland S, Hlatky MA, Khoury MJ, Macleod MR, Moher D, et al Increasing value and reducing waste in research design, conduct and analysis. Lancet. 2014;383:166-75.

4. ClinicalTrials.gov. ClinicalTrials.gov identifier (NCT number): NCT03089398 Available at: https://clinicaltrials.gov/ct2/show/NCT03089398. Accessed June 3, 2018. 